\title{
Sobre epidemias durante la Colonia
}

ENRIQUE LAVAL R.

\section{About epidemics during the Colony}

Durante la Colonia se produjeron algunas epidemias, de las cuales no hay datos suficientes ni fidedignos y que, como curiosidad histórica, reseñamos en esta ocasión.

Una epidemia de "dolor de costado y romadizo", se desarrolló en el año 1632, según dice el capitán Lazo de La Vega en carta a Felipe IV, ocasionándole La pérdida de La mayoría de sus soldados.

La epidemia llamada "quebrantahuesos" se presentó en 1658 y el Padre Rosales señala: que "molía a uno y le daban dolores vehementisimos y con esa calentura y encendimiento grandísimo de la sangre, con un dolor de estómago y flaqueza de cabeza que quitaba el juicio, y no era la peor señal de vida" (influenza).

En el año 1676, acompañó a un brote de viruela, otra enfermedad infecciosa, con gran elevación de la temperatura y que, según los cronistas de la época, producía una "muerte acelerada".

En 1737 ó 1743, sobrevino la epidemia de la "bola de fuego". El presidente don José Antonio Manso de Velasco tomó las medidas sanitarias que se conocían en el país, para aminorar los estragos del mal, que terminó según la tradición popular, con la caída de la "bola" fue aerolito que coincidió con la desaparición de la epidemia) a una isla desierta del archipiélago de Chile. Es muy probable que pudiera haberse tratado de influenza.

Durante los años 1779 y 1780, se presentó una enfermedad que atacó con saña a las ciudades de Concepción y Santiago, quizás por ser los centros más poblados. Fue denominada "El Malsito". Algunos la atribuyen a contagio traído por la escuadra del Almirante Vaccaro, enviada desde el Callao a Talcahuano para vigilar los corsarios ingleses; otros a "una descomposición atmosférica por un gran aluvión seguido de sequía". En cuanto a sus características se le ha dado una fisonomía gripal. Si bien algunos historiadores piensan que se trató de fiebre amarilla o colera. Para Carvallo y Goyeneche era una "calentura pátrida que mataba en tres días". Al parecer enfermó gran parte de la población, debiendo habilitarse en Santiago, dos hospitales provisorios, uno de hombres en eI Noviciado de los Jesuitas y otro de mujeres en la Casa de Huérfanos. 